\title{
EL ALMIRANTE PORTUGUÉS LANÇAROTE DA FRANCA, REDESCUBRIDOR DE LAS ISLAS CANARIAS. UNA FALSEDAD DEL SIGLO XIX
}

\author{
Alberto Quartapelle \\ cronicascanarias@gmail.com
}

\section{RESUMEN}

En 1925, el historiador portugués Fortunato de Almeida publicó, en su Historia de Portugal, tres documentos que testimoniaban las hazañas en las Islas Canarias de un cierto almirante Lansarote da Framqua (Lançarote da Franca), descubridor de dos Islas en el Atlántico, quien muriera ańos más tarde en lucha con los indígenas al intentar conquistarlas. En este artículo se tratará de demonstrar, también gracias a nuevos documentos que se publican por primera vez, que la existencia del almirante Lançarote da Franca es un falso histórico y que los documentos publicados por Almeida fueron probablemente concebidos a finales del siglo XIX*.

Palabras Clave: Lançarote da Franca, almirante de Portugal, redescubrimiento de las Islas Canarias.

\author{
THE PORTUGUESE ADMIRAL LANÇAROTE DA FRANCA, \\ REDISCOVERER OF THE CANARY ISLANDS. \\ $19^{\mathrm{TH}}$ CENTURY FALSENESS
}

\section{Abstract}

In 1925, in his History of Portugal, the Portuguese historian Fortunato de Almeida published three documents that testified the feats of a certain Admiral Lansarote da Framqua (Lançarote da Franca) in the Canary Islands. According to the documents he was the discoverer of two islands in the Atlantic and he died some years later in a battle against the natives when he was trying to conquer them. In this article we will try to demonstrate, thanks to new documents published for the first time, that the existence of the Admiral Lançarote da Franca is a fake history, and that the documents published by Almeida were probably conceived by the end of the 19th century.

Keywords: Lançarote da Franca, Admiral of Portugal, rediscovery of the Canary Islands. 


\section{INTRODUCCIÓN}

En 1925, en su Historia de Portugal, el historiador Fortunato de Almeida publicó tres documentos (doc. 1) ${ }^{1}$ que testimoniaban las hazañas de un cierto almirante Lansarote da Framqua (da Franca) en las Islas Canarias, quien descubriera dos islas en el Atlántico y años más tarde muriera en lucha con los indígenas es su intento por conquistarlas.

En el primer documento, fechado en 1370, el rey D. Fernando de Portugal concedía al almirante Lanzarote da Franca el Señorío de las islas de Nossa Senhora da Framqua (Lanzarote) y de la Gumeyra (¿Fuerteventura?), la cual recién había descubierto:

Don Fernando, por gracia de Dios Rey de Portugal y del Algarve [...] queriendo hacer gracia y merced a Lansarote da Framqua, almirante, [...] de las islas que encontró y nos ganó, que están en el mar del Cabo Non, las cuales no están pobladas, porque de ellas no hemos hecho merced a la persona que las habría de poblar y gobernar, [...] hacemos libre y pura donación [...] al mencionado Lansarote, nuestro almirante, para sí y para todos sus herederos y sucesores, de las dos primeras islas que encontró, de Nosa Señora a Framqua y de la Gumeyra, con todas sus tierras y rentas que tengan y hayan de tener...

En el segundo documento, fechado en 1376, el rey D. Fernando donaba a Lanzarote da Franca unas jabonerías como compensación, ya que este todavía no había podido tomar posesión de dichas islas debido a la guerra que se había entablado contra sus habitantes, los gaanchos, y contra los castellanos:

... ni al mencionado Lançarote se le ha entregado su natural posesión, por razón... de la guerra que hubo entre los mencionados gaãchos y los castellanos. Sin embargo, queriendo hacerle gracia y merced, como muy bien lo merece, confirmamos y mantenemos como Capitán Mayor de dichas islas al mencionado Lamsarote da Framqua, nuestro almirante de las galleas. Y [...] le hacemos donación, para siempre de las jabonerías negras de la Villa de Tavilla y de Castromarim y de Alcoutim y de la aldea de Martinlongo, en el reino del Algarve [...] al dicho Capitán Mayor y todos sus sucesores...

* Un sincero agradecimiento a Mário Farelo, investigador do Instituto de Estudos Medievais da NOVA Faculdade de Ciências Sociais e Humanas; a Mário Viana, profesor de História Medieval en la Universidade dos Açores; a Isabel João Ramires, de la Biblioteca Geral da Universidade de Coimbra.

1 Todos los documentos utilizados en este articulo están publicados en AcademiaEdu con el título Los documentos de Lançarote da Franca, el falso Almirante de Portugal: https://www.academia.edu/38443044/Los_documentos_de_Lan\%C3\%A7arote_da_Franca_el_falso_Almirante_ de_Portugal. (27.02.2019). El texto de los documentos citados se indicará con su respectivo número (doc. $\mathrm{x})$. All the documents used are published in AcademiaEdu with the title "The documents of Lançarote da Franca, the false Admiral of Portugal». https://www.academia.edu/38443044/Los documentos_de_Lan\%C3\%A7arote_da_Franca_el_falso_Almirante_de_Portugal. (02.22.2019). In the text of the article the cited documents will be indicated with their respective number (doc. $\mathrm{x}$ ). 
En el último documento, de 1385, el rey Don João le confirmaba al hijo de Lanzarote, Lopo Afonso da Franca, la donación de las jabonerías que el rey Don Fernando le había hecho a su padre, quien había tenido honrado fin en las Islas Canarias unos ańos antes:

... hacemos saber que Lopo Affonso da Framqua, caballero, nuestro vassalo, almirante de las galeas [...] considerados los muchos y buenos servicios de su padre, que Dios lo perdone, Capitán Mayor de las islas (de Lanzarote y de ¿¿Fuerteventura?) [...] que ahora ha tenido honrada fin en Lanzarote [...] le confirmamos las jabonerías negras de la Villa de Tavilla y de Castromarim y de Alcoutim y de la aldea de Martinlongo...

Después de que Almeida ${ }^{2}$ publicara el escrito, conocido desde entonces como «documento Almeida», los historiadores portugueses no mostraron particular interés en él. La razón de esta actitud está bien resumida por Franco Machado en una nota a la Historia da expansão portuguesa no mundo ${ }^{3}$ : «El documento publicado por Fortunato de Almeida [...] no está estudiado suficientemente para creer en su autenticidad». El motivo que justificaba la cautela de los historiadores residía en las circunstancias del hallazgo. El escrito, supuestamente adquirido en una venta pública de los archivos de la familia Franca, había desaparecido posteriormente y, por lo tanto, solo se había podido estudiar el texto publicado por Almeida, sin haberse tenido acceso al original.

Publicado nuevamente en 1944 por Silva Marques en su repertorio documental Descobrimientos Portugueses 4 , el documento Almeida no suscitó mayor clamor hasta que el historiador belga Verlinden ${ }^{5}$, en 1961, creyó reconocer en el Lanzarote da Franca del documento la figura del navegador Lanzarotto Malocello, cuyo nombre aparece en el mapa de Angelino Dulcert de 1339, al lado de la isla de Lanzarote, la más oriental de las Islas Canarias.

Elías Serra Ràfols, catedrático de Historia de la Universidad de La Laguna, estudió minuciosamente el texto portugués y, en abierto contraste con Verlinden, trató de demonstrar que se trataba de un «escrito falso, indigno de cualquier crédito" (doc. 16) .

La polémica «Verlinden-Serra» llegó a niveles raramente vistos entre los historiadores. En una reseña del trabajo de Verlinden, Miguel Santiago lo definió como "perturbador de la investigación sobre los primeros tiempos del redescubri-

2 Fortunato de Almeida (2004): História de Portugal, volumen II, Bertrand Editora, pp. 721-730.

${ }^{3}$ Franco Machado (1937): História da expansão Portuguesa no mundo, Editorial Ática Lisboa, vol. I, nota 2 p. 272.

${ }_{4}^{4}$ Marqués, S. (1971): Descobrimientos portugueses, vol. 1, p. 186, Lisboa.

5 Verlinden, C. (1976): «La découvert des archipels de la Méditerranée atlantique», Revista de Historia de Portugal, t. 16, pp. 105-131.

'Serra RÀfols, E. (1961): «El redescubrimiento de las Islas Canarias en el siglo XIV», Revista de Historia Canaria, n. ${ }^{\text {os }} 135-136$, pp. 220-234. 
miento de las Canarias» ${ }^{7}$. Por su parte, Hernández Pereira consideró que el documento Almeida era una "burda superchería»" y finalmente Serra censuró a Verlinden por someter a una «ruda contorsión todos los hechos que conocíamos de la historia de Canarias» y por «interpretar [las fuentes historiográficas] a la fuerza y de manera desconcertante».

La polémica fue tan feroz que, para reforzar la idea de la falsedad del documento, Serra escribió: «Su autenticidad fue en seguida puesta en tela de juicio y después razonadamente rechazada por los críticos», citando como prueba al historiador portugués Jaime Cortesão, quien, según Serra, "comentaba dubitativamente los documentos publicados por Fortunato de Almeida». En realidad, Cortesão en un artículo del 29 de junio de 1925 había expresado una opinión algo diferente: «Desde los documentos se puede concluir que la familia da Franca tuvo parte preponderante si no en el descubrimiento, por lo menos en los intentos de conquista de las islas [Canarias] $»$.

En su respuesta a Serra, Verlinden no fue menos agresivo y lo acusó tanto de contradecir su teoría como de considerar falso el documento Almeida solo porque «molestaba vivamente al patriota español $»^{10}$, y también acabó ofendiendo a otro crítico, el portugués Luis de Albuquerque, calificándolo prácticamente de ignorante ${ }^{11}$.

Actualmente las opiniones acerca de la autenticidad del documento Almeida, y del viaje de Lançarote da Franca a las Islas Canarias, ubican a los historiadores en dos bandos contrapuestos: los españoles le niegan cualquier valor histórico, mientras que los portugueses lo consideran, a veces con algún margen de incertidumbre, auténticos.

Para tratar de solucionar esta radical diferencia de opiniones entre historiadores, se han verificado las informaciones contenidas en el documento Almeida con apoyo de documentos de la época, algunos estudiados por primera vez. Esta verificación ha permitido poner en evidencia informaciones que pueden ser históricamente comprobadas, informaciones que no se pueden comprobar totalmente pero que, sin embargo, están en el campo de lo posible, e informaciones que, basándose en los conocimientos actuales, deben considerarse falsas.

\section{LAS CRÍTICAS DE LOS HISTORIADORES}

Desde su aparición, el documento Almeida ha sido objeto de estudio por parte de varios historiadores, quienes han tratado de encontrar posibles errores en su redacción. Serra Ràfols, el historiador que se mostró más abiertamente contra-

7 Santiago, M. (1960): Anuario de Estudios Atlánticos, 6, p. 615.

${ }^{8}$ Hernández Perera, J.: Revista de Historia Canaria 14, Notas bibliográficas, pp. 392-394.

9 En Fortunato de Almeida, ibidem.

${ }^{10}$ Verlinden, C.: Protocolonialismo extranjero y colonización ibérica en la zona atlántica, p. 651.

11 Verlinden, C. (1976): «La decouverte des archipels de la Mediterranée atlantique (Canaries, Madères, Acores)", Revista de Historia de Portugal, t. 16, pp. 105-131. 
rio a la autenticidad del documento Almeida, en sus críticas denunció varios posibles anacronismos entre el texto y los conocimientos geográficos e históricos que se tenían en la época de su supuesta redacción. Críticas que, sin embargo, no tienen fundamento:

\section{A. El «Mar del Cabo de Non»}

En palabras de Serra, «[el documento Almeida] sitúa a las islas en el mar del Cabo de Nẫo. Este cabo, en efecto, se halla ya consignado, aunque sin especial relevancia, en los portulanos normales. [...] Pero lo que es un completo anacronismo es la expresión "Mar del Cabo de Non". Esta idea de los mares particulares, como partes del mar general u Océano, era totalmente desconocida hasta para los geógrafos teóricos del Renacimiento. La expresión Mar Mediterráneo no fue usada ni siquiera una vez en los portulanos o documentos medievales».

Los textos geográficos de la época del documento Almeida no confirman esta afirmación de Serra. Por ejemplo, en el De insulis, el islario escrito por De Silvestri cerca del 1400, se indican más de veinte mares particulares de todo el mundo ${ }^{12}$, como el mar Helesponto, el Índico, el Adriático, el de Córcega, el Egeo y el Rubro.

También el Libro del conocimiento del siglo XIV, uno de los primeros textos geográficos que mencionan a las Islas Canarias, no solo hace referencia a varios mares particulares ${ }^{13}$, incluyendo el mar Mediterráneo, sino que ofrece la explicación del por qué tienen diferentes nombres. Hablando del actual Mar Caspio explica que «... le dizen el Mar Caspio por los montes Caspios que y llegan, et dizen le el Mar de la Jorgania por que la ha por vezina, et dizen le el mar de Quillan por una provincia que es en su ribera que dizen Quillan, et dizen le el Mar de Sara por la prorrogatura del imperio de Sarra, et dizen la el Mar Bacu por la cibdad de Bacu...». No debería extrañar, por lo tanto, que además de un «Cabo de Non» existiera también un «mar de Cabo de Non».

\section{B. El etnónimo GAĀCHOS}

El segundo supuesto anacronismo propuesto por Serra está relacionado con el uso, en el documento, de la palabra gaãchos para indicar a los antiguos moradores de las Islas Canarias.

${ }_{12}$ Domenico Silvestri, De insulis et earum proprietatibus: Ellesponti, Indici, Illirico, Adriatici, Greci, Rubro, Affrico, Fenicei, Asiatici, Cyrneum Tusci, Corsici, Ionio sinu Adriatici, Propontide, Egei, Hyspani, occeano Ethiopico, Hexperici, Britannici, Sirii, Egiptii, Gallici, Ligustini, etc.

${ }^{13}$ Libro del conocimiento: mar Occidental, de Poniente, Medio Terreno, Mar de golfo de Loira, de Alemania, Mayor, de Ancona, Mediterráneo, de india, Rubro, Perticum, Negro, Verde, de Java, Mare tabasur, de Letana, etc. 
De acuerdo con Serra: «... lo que no puede explicarse siquiera por una casual anticipación de usos de lenguaje es el nombre gaächos, como sinónimo de naturales de las islas de Lanzarote y La Gomera, que emplea el texto de 1376. Este nombre nos es bien conocido: es una ligera alteración de guanches, nombre gentilicio con que fueron designados los naturales de Tenerife por sus conquistadores castellanos de fines del siglo xv. Ahora bien, aun para estos isleños de Tenerife, el nombre no entró en uso hasta el último cuarto de dicho siglo xv; y además su uso extensivo, y sin duda abusivo, para designar cualesquiera nativos de las Islas Canarias es modernísimo, pues no se remonta más allá del siglo pasado, adoptado por ciertos eruditos, sobre todo extranjeros, como Bertelot y Verneau, felices de disponer de un nombre propio para la supuesta nación indígena... Alguna vulgarización histórica de Canarias caería en manos del autor del documento Almeida, y creyó que el uso de este término característico autorizaría su engendro, pues era una palabra local que solo quien estuvo en real contacto con las Islas podía conocer. Pero, por malaventura suya, a nadie antes de la mitad del siglo xix se le pudo ocurrir llamar guanches a los nativos de Lanzarote o de La Gomera. Esta huella digital, por sí sola, basta para condenar toda la superchería [del documento Almeida]».

Como afirma Serra correctamente, el etnónimo guanche no apareció en los textos etnohistóricos de Canarias hasta finales del siglo xv. En realidad, los primeros cronistas del descubrimiento no demostraron un gran interés por encontrar un nombre para los habitantes de las Islas Canarias. En el primer relato acerca de las islas y de sus moradores, el de al-Maqrízl de 1339, los habitantes de las islas son llamados apenas «pobladores», mientras que en la crónica del viaje de Da Recco de 1341, los naturales son simplemente "gentes», "habitantes» e «insulares» ${ }^{14}$.

Solo a comienzos del siglo xv en Le Canarien (1402), la crónica de la conquista de Gadifer y Bethencourt, aparece por primera vez el etnónimo canario para indicar a los habitantes de las islas, tanto sea como referencia general a los naturales de todas las islas como en especial a los de alguna de ellas.

La primera vez que se documenta la voz guanche es en las Memorias del reynado de los Reyes Católicos de Bernaldez (1495-1512), referida a los habitantes de Tenerife: «E arribaron en Tenerife e tornaron tierra e començaron de hazer la guerra a los guanches que así se llamaban aquella nación de gente» ${ }^{15}$. En general, en las crónicas y en los relatos de los viajeros se llama de forma inequívoca guanches solo a los aborígenes de Tenerife. Los naturales de las otras islas reciben el nombre de canarios, o el de mahoreros a los de Lanzarote, o de gomeros a los de La Gomera ${ }^{16}$, y de majos a los de Lanzarote.

${ }^{14}$ En su relato, Cadamosto (1455) hace una simple distinción entre los moradores europeos, los «cristianos», y los nativos, calificados todos como «idólatras».

15 Bernáldez, Andrés (1978): «Memorias del reynado de los Reyes Católicos», cap. cxxxiv, en Morales Padrón, F., Canarias: crónicas de la conquista, El Museo Canario Las Palmas, pp. 506-520.

16 Trapero, Maximiano (2007): Estudios sobre el guanche, Fundación Mapfre Guanarteme, Las Palmas de Gran Canaria, p. 125, pp. 130-131. 
Si este es el uso más común que se le da al término guanche, no faltan las excepciones que ponen en duda la afirmación de Serra Ràfols de que «el uso extensivo [de guanche] [...] para designar cualesquiera nativos de las Islas Canarias es modernísimo, pues no se remonta más allá del siglo pasado». En realidad, el uso del gentilicio guanche para designar a los habitantes de todas las islas, y no solamente a los de la isla de Tenerife, lejos de ser un modernismo inventado por Bertelot y Verneau, se remonta al siglo Xvi, siendo el primero en utilizarlo Alonso de Santa Cruz en 1546: «Y tomaron en ella [(Tenerife] tierra y comenzaron a hacer guerra a los guanches, que así se llamaban los habitadores de aquellas yslas...». Y en el mismo sentido general lo usaron también Pérez de Torres (1586): «Estas son las Islas de las Canarias, stan de España trecientas leguas, llamamos a su gente guanches»; Jan van Linschoten (1610): «Las islas Canarias [...] hoy están habitadas por españoles mezclados con los naturales del país llamados Guancha»; Fernandez Brandao (1618): «Que las Islas Canarias, que estaban pobladas, antes de ser descubiertas por los castellanos, por personas a las que llaman Guanches»; y José de Sosa (1678), quien al hablar de los habitantes de Gran Canarias los llama "canarios guanches».

Un segundo aspecto que pone en tela de juicio la tesis de Serra de que el término guanche haya tenido en la antigüedad un uso exclusivo en la isla de Tenerife es su difusión entre los topónimos de todas las islas. En el caso de la isla de Lanzarote, por ejemplo, el número de topónimos que emplean de una u otra forma el término guanche es equivalente a los que utilizan el de majo, nombre de sus antiguos pobladores. Y una difusión similar se encuentra también en las otras islas. Como ha hecho notar Agustín Pallares, hay «serias dudas respecto a la legitimidad de ese pretendido exclusivismo del término guanche para la isla de Tenerife» ${ }^{17}$.

El documento Almeida, y la utilización de la palabra gaanchos en él, podría no estar tampoco en contraste con la teoría del filólogo canario Maxiero, quien plantea la hipótesis de un origen francés para el termino guanche: «El argumento lingüístico en favor del galicismo no puede ser más sencillo: en francés antiguo y en francés medio existía la palabra guanche, escrita con esta misma ortografía y pronunciada prácticamente igual que la palabra homógrafa del español actual, en la época en que Jean de Béthencourt conquistó las Islas Canarias. Pero lo asombroso y revelador para quien pudiera dudar del origen francés, es que el verbo guenchir y el sustantivo guenche designan, en sus diferentes acepciones, exactamente las acciones y aptitudes que de los primitivos canarios fueron descritas en las crónicas antiguas, como las más llamativas, las más características, a los ojos de un extranjero... de aquel que esquivaba un arma arrojadiza girando su cuerpo, el que se gira, el ágil $\aleph^{18}$. Si el origen del término guanches fuera francés no debería sorprender que

17 Pallares, Agustín (1986): «Consideraciones sobre el gentilicio guanche», La Provincia de Las Palmas, 12-IX-1986.

${ }_{18}$ Trapero, Maximiano (2007): Estudios sobre el guanche, Fundación Mapfre Guanarteme, Las Palmas de Gran Canaria, p. 125, pp. 164 y 173. 
pudiera haber sido utilizado, deformado en portugués como gaanchos, por un navegante como Lanzarote, cuyo apellido era «da Francia».

\section{El uso del nombre «Nossa Senhora da Framqua»}

Las críticas de Serra no se refieren solo a unos supuestos anacronismos entre los conocimientos propios del siglo XIV y el contenido del documento Almeida, sino que apuntan también a otros aspectos: en palabras de Serra: «La isla de Lanzarote es llamada de Nossa Senhora da Framqua; el autor del documento (Almeida), no demasiado conocedor de las cosas canarias, seguramente no conocía otro nombre de la isla que este que aparece desde el primer portulano, Insola de Lansarote, el cual no creyó que fuera conveniente usar cuando su héroe acababa de descubrirla, e inventó el de Nuestra Señora de Francia, que todavía contenía el apellido adscrito por él a Lancelotto (da Framquia) y una advocación piadosa muy propia del tiempo y que, acaso sabía, tuvo culto especial en las Islas Canarias».

La tesis de Serra es que el falsario del documento Almeida, no pudiendo llamar a la isla que recién había descubierto con el nombre de su descubridor, Lanzarote, inventó el nombre de Nuestra Senhora da Framqua (de Francia) utilizando una advocación de la Virgen supuestamente bien conocida en Canarias. Las referencias ofrecidas por Serra no son suficientes para identificar cuál sería la advocación mariana que "tuvo culto especial en las Islas Canarias» a la que él se refiere. En realidad, no parece haber existido en Canarias un culto a Nuestra Seńora de Francia. Posiblemente Serra confunde esta advocación con otra, la de Nuestra Señora de Peña de Francia, cuya iglesia, edificada en Puerto de la Cruz (Tenerife) en 1603, es conocida también por encontrarse allí la estatua de la Virgen del Carmen, y cuyo culto procede de la localidad española de Peña de Francia, una montańa que se levanta al sur de la provincia de Salamanca, en el límite con la de Cáceres.

En cualquier caso, si realmente el falsario portugués decidió inventar el nombre de Nuestra Senhora da Framqua (a Franca), no tuvo necesidad de mirar hacia las Islas Canarias. Aunque no fuera un culto muy popular en Portugal, hay dos capillas dedicadas a esta advocación de "Franca», o sea, la Generosa, una en Lisboa, en la iglesia parroquial de Santiago, y otra en la ciudad de Tavira ${ }^{19}$. Y, por cierto, el culto a Nuestra Seńora a Franca está relacionado con la familia Franca, por lo menos desde en 1430, como recuerda el genealogista Dom Flaminio de Sousa en su Nobiliario: «Vasco Lopes da Franca es juez de la Senhora a Franca» (doc 6).

19 Bluteau, R. (1713): Vocabulario portuguez, e latino ... autorizado com exemplos dos melhores escrotores portuguezes e latinos, Cologio das artes de la Companhia de Jesus, Coimbra, p. 199. 
En opinión de Serra, otro «... obstáculo que se presenta [para aceptar el documento Almeida] [...] es el Libro del Conoscimiento de todos los reynos, que desde mitad del siglo XIV (1350) nos cuenta ya la historia de la muerte de Lanzarote en su isla...». El supuesto error al que, en este caso, hace referencia Serra se basa en el relato de la muerte de Lanzarotto Malocello que nos ha consignado el Libro del conocimiento: «La isla de Lançarote et dizen le asy porqué las gentes desta isla mataron a un ginoves que dezian Lançarote». De acuerdo con Serra, el Libro habría sido escrito en 1350 y, por lo tanto, la fecha real de la muerte de Lanzarote sería muy anterior a la indicada en el documento Almeida, en el cual Lanzarote da Franca habría muerto luchando con los gaanchos entre 1376 y 1385. Esta aparente contradicción se debe, en realidad, solo a un error en la datación del Libro del conocimiento.

El Libro del Conoscimiento de todos los reinos et tierras et señorios que son por el mundo, et de las señales et armas que han cada tierra et señorio por sy et de los reyes et señores que los proveen es uno de los primeros textos de geografía universal del mundo conocido en la Edad Media. Esta obra, interesantísima para el conocimiento que entonces se tenía de la tierra, fue publicada por primera vez en 1877. Es probable que haya sido escrita por un fraile y se remonte, sin duda, al siglo xIV, porque fue utilizada por el fraile Pierre Boutier en su crónica de la conquista de Canarias, conocida como Le Canarien y escrita posiblemente en 1420.

A través del Libro, el relato de un viaje, tal vez imaginario, por todo el mundo conocido, sabemos que el autor nació en España en 1304 o 1305, aunque no haya indicaciones de la época de su redacción. Por este motivo, los historiadores han tratado de deducirla utilizando los acontecimientos narrados en el texto. Según Bonnet $^{20}:$ «De los sucesos consignados en la narración, el más reciente no pasa del año 1348, que es la derrota de Abulhasán Alí junto a Kairhuan; por consiguiente, el libro puede fecharse hacia el año 1350».

En realidad, los estudios del historiador y experto francés en heráldica Martin de Riquer ${ }^{21}$ han permitido plantear la hipótesis de una fecha de redacción mucho más tardía, posterior a 1375. Para llegar a esta conclusión, Riquer ha estudiado no solamente la descripción de los lugares y acontecimientos presentes en el Libro, sino también el centenar de armas heráldicas de soberanos, países y ciudades ilustrados con dibujos realizados de forma razonablemente correcta.

El blasón más interesante para aclarar el tema de la datación del Libro es el del rey de Francia, que «á por señales un pendón azul con tres flores de lis de oro». De acuerdo con Riquer, los reyes de Francia, en toda clase de documentos y ornamentos, desde Felipe Augusto usaron un emblema con un sembrado de flores y solo

${ }^{20}$ Bonnet, B. (1944): «Las Canarias y el primer libro de Geografía medieval escrito por un fraile español en 1350», Revista de Historia, n. ${ }^{\circ}$ 67, p. 207.

${ }^{21}$ Riquer, Martin de (1987): «La heráldica en el Libro del Conoscimiento y el problema de su datación", Cuadernos de Filología Hispánica, n. ${ }^{\circ}$ 6, pp. 313-319. Edit. Univ. Complut Madrid. 
Carlos V, a partir del año 1376, lo hizo con un escudo en el que había apenas tres flores de lis. Hecho este que haría pensar que la redacción fue finalizada después de 1376, fecha compatible con la asumida para la muerte de Lanzarote da Franca, que el documento Almeida ubica entre el 7 de julio de 1376 y el 8 de noviembre de 1385 .

\section{E. LAS ISLAS «QUE NO ESTÁN POBLADAS»}

Otra crítica al documento se ha dirigido a la expresión nom som pobradas referida a las dos islas recién descubiertas por Lanzarote da Franca, que aparece en el documento de 1370. Esta afirmación está en oposición al relato de Boccaccio del viaje de $\mathrm{Da}$ Recco de 1341, que nos informa que todas las islas mayores estaban pobladas, circunstancia confirmada también por el Libro del conocimiento: «E todas estas yslas non eran pobladas de gentes más de tres que son Canaria et Lançarote et Forte Ventura».

De acuerdo con el historiador portugués Luis de Albuquerque, no hay contradicción si se interpreta la palabra pobradas en un sentido restringido, considerando como habitantes solo a los cristianos ${ }^{22}$. Aún más convincente parece el razonamiento de Verlinden, quien para explicar la frase «no están pobladas, porque de ellas no hemos hecho merced a la persona que las habría de poblar y gobernar» sugiere que «esto no quiere decir que las islas en cuestión no estaban habitadas por indígenas, más bien que no habían estado donadas en vista de asegurar el poblamiento por parte de colonos, que quiere decir que no se había hecho lo que más tarde se llamaría, durante la colonización española, el repartimiento. La repartición de las tierras a los colonos se hacía, en efecto, por un emprendedor de la colonización. Cuando a comienzos del siglo Xv Jean de Betancourt se establece como vasallo del rey de Castilla en Lanzarote y Fuerteventura, hace el repartimiento de las tierras».

\section{UNAS HUELLAS DE AUTENTICIDAD HISTÓRICA}

Para poner en tela de juicio el documento Almeida, Luis de Albuquerque en su Introducão à história dos descobrimentos portugueses hace notar que «en ningún otro escrito se encuentra la más pequeña citación a los hechos allí [en Almeida] referidos, y nadie hasta el momento de su publicación sospechaba ni siquiera su existencia». Esta afirmación es correcta si se refiere a los hechos más importantes citados por el documento Almeida. Sin embargo, hay varios hechos secundarios que tienen una parcial confirmación en los archivos.

22 Albuquerque, Luis de (1983-?): Introdução à história dos descobrimentos portugueses, Publicações Europa-América 3. ${ }^{a}$ edición. Lisboa, pp. 94-102. 


\section{A. El personaje de Lanzarote da Franca}

Analizando el documento Almeida, los historiadores han dirigido la atención a la figura de Lanzarote da Franca, de cuyo origen no se sabe mucho. El vizconde de Baena, autor del libro de genealogías portuguesas Familias nobres do Algarve, creyó que Lanzarote da Franca podría haber alcanzado Portugal mucho más tarde, para la época del reinado de D. João I (1385-1433) (doc. 12). Por su parte, Fortunato de Almeida propuso la hipótesis de que «el Lançarote de Franca de nuestros documentos es el mismo almirante que otros documentos y escritores llaman Lançarote Pecanha». Esta identificación no es todavía históricamente real porque Lanzarote Pessagno murió el 12 de octubre de 1385 en la insurrección de Berija, mientras que el documento de 1385 afirma que Da Franca había tenido «honrada muerte en la [isla] de Lanzarote».

En respuesta a Almeida, el genealogista portugués Afonso de Dornelas ${ }^{23}$, al estudiar las armas de las familias nobles de Europa, llegó a una conclusión diferente, reconociendo a los Da Franca como una noble familia francesa: «La semejanza es tan grande entre las armas y son tan similares los apellidos Franca y Franc que no queda duda que la familia portuguesa Franca tiene su descendencia de la familia francesa Franc d'Anglure».

Otra hipótesis acerca de la identidad de Lanzarote da Franca fue la presentada, muchos años antes de que apareciera el documento Almeida, por Almeida Pessanha, un descendiente de los almirantes Pessagno. En su biografía Os almirantes Pessanhas y sua descendencia propuso la siguiente hipótesis: «¿Acaso sería este Lançarote [Da Franca], uno de los veinte genoveses sabedores de mar, Lanzarotto de Franchi?». Hoy sabemos que la identificación entre la familia Da Franca y los De Franchi de Génova no es históricamente posible. El apellido De Franchi se utilizó por primera vez en Génova recién a partir del año 1393, debido a la creación de un Albergo, peculiar institución que caracterizó a la estructura política y social de esta ciudad desde el final del siglo xiv. Contrariamente a lo que sucedía en muchas otras naciones, Génova debía su designación como potencia política, militar y comercial en el Mediterráneo, mar Negro y Europa del Norte más a la iniciativa privada que a la organización estatal, hasta el punto de que Génova no tenía una flota del Estado, y en caso de peligro se apoyaba en las galeras de las familias más influyentes, los Boccanegra, los Fieschi, los Spinola, los Grimaldi, los Doria. Cuando la dimensión familiar resultó demasiado pequeña como para sostener el creciente poder dentro y fuera de la República, los genoveses crearon entonces una nueva institución, el Albergo, unión de varias familias que aceptaban integrarse en una entidad nueva y más grande. El Albergo, al momento de su constitución, podía utilizar libremente el apellido de una de las familias que lo integraban, o podía inventar uno nuevo, como en el caso del Albergo de Franchi, constituido en Génova el 28 de enero de 1393 y conformado por 15 familias, ninguna de las cuales se llamaba Franchi. El

${ }^{23}$ Dornelas, Afonso de en Historia de Portugal de Fortunato de Almeida, pp. 728-730. 
apellido Da Franca, que aparece en el documento Almeida de 1370, no puede entonces derivar del apellido Franchi, que hizo su aparición recién veinte años más tarde.

Volviendo a la realidad históricamente comprobada, en la época existió efectivamente en Portugal un Lançarote da Franca, habitante de la ciudad de Tavira: hasta ahora se ha tenido conocimiento de este personaje gracias a dos genealogistas del siglo xx que, sin embargo, lo ubican en dos diferentes períodos históricos: Almeida Pessanha en el tiempo de D. Diniz (1261-1325) y el vizconde Sanchez de Baena en el tiempo de D. Joao I (1385-1433). Circunstancia que sería incompatible con el Lançarote da Franca Almirante das gallees del documento Almeida de 1370.

Sin embargo, el dato ofrecido por De Baena no es correcto: en su «Familia nobres do Algarve», él escribe ${ }^{24}$ : «Lanzarote da Franca, el primero con quien el notable genealogista Dom Flaminio empieza esta familia por haber conseguido darle una sucesión continua hasta el siglo pasado. Lanzarote da Franca llegó en el tiempo del reynado de D. Joao I y se casò con D. Leonor d'Abreu, hija de Lopo Vaz de Castello Branco, Monteiro Mór del Rey D. Joao». Sin embargo, controlando el manuscrito original de Dom Flaminio en la Biblioteca de Coimbra (doc. 6), se ha podido averiguar que en el no aparece el nombre de un Lançarote da Franca hasta el $1424^{25}$.

Por lo contrario, correcta es la genealogía propuesta por Almeida Pessanha en su Os Almirantes Pessanhas e sua descendencia, que se funda en el nobiliario de Rangel de Machedo (doc. 7): «Manuel Pessanha (el $1^{\circ}$ Almirante de Portugal nomeado por D. Diniz en 1317) casou com Leonor Afonso, filha de Lançarote da Franca, morador em Tavira». Controlando por primera vez el nobiliario de otro genealogista del siglo XVII, Belchor de Andrade Leitao (doc. 4), que pudo leer de primera mano documentos hoy perdidos, se ha encontrado una nota que confirma la existencia de este Lançarote da Franca: «Micer Manoel Peçano [...] casou 2. ${ }^{a}$ vez com Leonor Affonso filha de Lançarote da Franca morador em Tavira. (nota al margen: No Livro preto da Câmara de Tavira, fl. 113, diz um aforamento feito no ano de 1392 que fez esta Leonor Afonso, almiranta, a Afonso Nunes, de terras em Majaleira)». Desafortunadamente el Livro da Câmara de Tavira está hoy perdido.

24 «Lançarote da Franca, o primero em quem o notavel genealogista Dom Flaminio dá començo a esta familia por ter conseguido dar-lhe uma successão continuada até ao no seculo pasado. Lançarote da Franca alcançou o reinado de D. João I, tempo em que casou com D. Leonor d'Abreu, filha de Lopo Vaz de Castello Branco, Monteiro Mór do Rey D. Joao».

${ }_{25}$ Los primeros Da Franca de los que Dom Flaminio nos ha transmitido su existencia fueron un Fernando Antonio, un Lopo Antonio y un Antonio Lopes da Franca en 1424. En realidad, Sanchez de Baena utiliza para su genealogía las informaciones de otro genealogista, Rangel de Macedo, que no se sustentan en ningún documento de la época. 
Como hemos visto en el documento Almeida de 1376 y 1385, se hace referencia a la «donación para siempre» a Lançarote da Franca y a su hijo Lopo Afonso «de las jabonerías negras de la Villa de Tavilla y de Castromarim, y de Alcoutim y de la aldea de Martinlongo, en el reino del Algarve». Como prueba de la existencia de una donación a los Franca de estas jabonerías puede citarse un documento de D. João de 1487 en el que hace merced a Diogo Lopes da Framqua «das minhas saboarias [...] que tenía por carta de la infanta D. Beatriz» ${ }^{26}$. Y, como nos informa el genealogista Dom Flaminio, la donación se remontaba por lo menos a 1473 (doc. 6).

\section{LOS ASPECTOS FormaLES}

Uno de los aspectos que podría hacer pensar que el documento es auténtico radica en el estilo del texto, que se corresponde con los de la época de D. Fernando y de D. João I, como confirmó en su tiempo el paleógrafo Pedro de Azevedo, el primero en examinar una copia ${ }^{27}$. Y el historiador Luis de Albuquerque, quien por cierto no creía en su autenticidad, pudo encontrar solo pequeñas anomalías como el uso del vocablo «fim» (final) en género masculino, cuando era más frecuente su uso en género femenino ${ }^{28}$.

En segundo lugar, se ha podido comprobar que los lugares en los que fueron supuestamente escritos los documentos Almeida se corresponden, en fecha y lugar, con los indicados en los itinerarios de D. Fernando y de D. João en las mismas fechas. Y se corresponde también con el nombre de los tabelliones que los redactaron: el documento del 29 de junio de 1370, por ejemplo, está redactado en Santarem por uasco uicête bacharel. El estudio de los itinerarios de D. Fernando ha permitido comprobar que desde el 19 de junio hasta el 18 de julio de 1370, el rey se encontraba efectivamente en Santarem y que el tabellion de todos los actos era Bascherel ${ }^{29}$; en el caso del documento del 7 de julio de 1376, escrito en Vila Nova da Rainha por steuam paaez, se ha comprobado que para esa fecha D. Fernando se

26 «A quamtos Esta minha carta virem faco saber que avemdo em rrespeito aos muytos seruicos que diogo llopez da framqua caualeiro de minha cassa tem feito ao Jmfamte meu Sennhor E padre (d. Fernando) que deos aja Espero que ao diamte a mym fara E queremdo lhe fazer graça e merçe Tenho por bem e lhe faco merce daquy em diamte das minhas Saboarias da uilla de tauilla alcoutim castro marim e d aldea de martym lomguo. Esto a quamto a mym prouuer asy e pella gysa que as elle athe ora thede per carta da Jmfamte minha Sennhora (D. Beatriz) isto enquanto eu quiser e como ele tem até agora por carta da infanta minha senhora». Caderno dos Registos das Comfirmaçoees d el Rey e primçepe nosso Sennhor comcertado Em a çidade de lixboa aos tres dias do mes de março do anno do naçimemto de nosso Sennhor Jhesuu crispto de mjll iiij ${ }^{c}$ LRviijo anos (doc. 13).

${ }_{27}$ Chancelaria regia, Arquivo Nacional Torre do Tombo.

${ }_{28}$ Albuquerque, Luís de: Introdução à história dos descobrimentos portugueses, Publicaçôes Europa-América, p. 97.

${ }^{29}$ Ch D. Fernando, Liv. 1 fl. 163 a 167. 
encontraba en la zona, el 4 y el 8 en Alenquer, el 11 en Vila Nova da Rainha y el 13 y 17 nuevamente en Alenquer, siendo tabellion $\mathrm{Paez}^{30}$; por último, en el caso del documento de D. João del 9 de noviembre de 1385, hecho en Guimarães por rodrigalvarez, tenemos otro acto escrito exactamente en esa misma fecha justamente en Guimaräes por rodrigalvarez ${ }^{31}$.

\section{LAS RAZONES PARA PENSAR EN UN DOCUMENTO FALSO}

\section{A. El título de almirante de Portugal}

Los historiadores que han puesto en tela de juicio la autenticidad del documento Almeida han focalizado su atención en el título de almirante, utilizado para referirse a Lanzarote da Franca y a su hijo Lopo Afonso. Esta crítica es relevante porque el título de Almirante-mor de la marina portuguesa ha tenido en el siglo XIV la doble naturaleza de cargo administrativo y de relación de vasallaje feudal. Instituido por el rey Diniz en 1317 en favor del genovés Micer Manuel Pessanha (Pessagno), el cargo de Almirante-mor tenía las dos obligaciones principales de defender al rey en el mar "contra todos homens do mundo [...] que seiam tambem christàaos como mouros» ${ }^{32}$, y mantener en Portugal veinte hombres de Génova sabedores do mar para ser alcaides das galés e arraes ${ }^{33}$. Como vasallo, el Almirante tenía que prestar juramento de fidelidad al rey, recibía la jurisdicción del lugar de la Pedreira en Lisboa y una renta vitalicia de 3000 libras en metálico. Título y renta que eran concedidos per manejra de moogado, o sea, que eran un derecho que se trasmitía a los hijos primogénitos varones legítimos y laicos.

Debido a que su trasmisión era hereditaria, el cargo de Almirante-mor, en el transcurso de los 137 años que van de 1317 a 1454, se mantuvo sin interrupción en posesión de la familia Pessagno ${ }^{34}$. Por ejemplo, cuando el Almirante Lanzarote Pessagno fue suspendido del cargo, por su derrota en la defensa de Lisboa en la guerra contra Enrique II de Castilla, su substituto, el hermano de la Reyna Leonora Afonso de Telos, no recibió oficialmente el título de almirante. Por cierto, la única vez que el título de almirante se trasmitió fuera de la familia Pessagno fue cuando D. Pedro de Menes, primer Conde de Villareal, lo recibió como dote de la esposa al

${ }^{30}$ Ch. D. Fernando, Liv. 1 fl. $194 \mathrm{v}$ a $195 \mathrm{v}$.

31 ANNT. Ch de João I, livro 1, fl. 160.

32 Regina Fernández, Fátima (2001): «Los Genoveses de la armada portuguesa: los Pessanha", Edad Media: Revista de Historia, n. ${ }^{\circ} 4$.

${ }^{33}$ Una expresión similar se encuentra también en la Primera crónica general: estoria de España que mandó componer Alfonso el Sabio, donde, hablando del almirante Ramón de Bonifaz y Camargo, que conquistó Sevilla en 1284, se escribe: «Remont Bonifaz et con los otros omnes buenos de las naues que eran sabidores de la mar». Primera crónica..., Madrid Bailly-Baillier, 1906, p. 765.

34 Almeida Pessanha, J.B. de (1923): Os almirantes Pessanhas e sua descendencia, Imprensa portuguesa Porto, 1923, pp. 55-56. 
casarse en 1430 con D. Genebra, hija del almirante Carlos Pessanha. Sin embargo, al fallecer D. Pedro sin haber tenido hijos varones, el título volvió a las manos del suegro, Carlos Pessagno ${ }^{35}$.

Es evidente que la exclusividad y continuidad hereditaria en el cargo de Almirante de la familia Pessagno sería incompatible con la contemporánea existencia de otros Almirantes de la familia Da Franca, como pretende el documento Almeida fechado el 2 de noviembre de 1370. En el Lançarote da Franca es llamado Almyrante das galles, pero sabemos que el titular del almirantazgo era en ese momento Lanzarote Pessagno al mando de la «gram frota des gallees e naos», enviada por el rey Dom Fernando al bloqueo de Sevilla y en la que, de acuerdo con la Crónica de Antão Lopes, «hia por almirante nas galles Mice Lamsarote Pecanho» ${ }^{36}$.

Para superar esta incongruencia, Fortunato de Almeida identificó en una única persona a Lanzarote da Franca y a Lanzarote Pessagno, hijo de Manuel Pessagno y segundo Almirante de Portugal desde 1356 hasta 1384. Sin embargo, de acuerdo con la historiadora italiana D’Arienzo ${ }^{37}$, «si por Lanzarote da Franca se podía jugar en la homonimia con Lanzaroto Pessagno, en el caso de Lopo Afonso no hay ninguna posibilidad de equivocación. Para esa época (1385) era, sin duda, Almirante Manuele II Pessagno, que había sucedido a su padre Lanzarote y cuya actividad está atestiguada en las crónicas». En la confirmación de sus derechos como señor de Odemira, hecha por el rey D. João I, Manuel Pessanha es nombrado el 2 de junio de 1385 «almirante de nosso irmâo el rey Dom Fernando a que Deus perdoe»"

Por cierto, hasta el momento, esta es la crítica de mayor relevancia que se ha presentado contra el documento Almeida, ya que no disponemos de ningún documento que utilice el término Almirante sin referirlo directa o indirectamente a un miembro de la familia Pessagno o a D. Pedro de Meneses.

35 Pereira Gonçalves, M. (2014-2015): Ammiragliato-Estudo Sociológico Sobre os Almirantes mores de Portugal, de D. Dinis a D. Afonso V (1279-1481)», en Omni Tempore, p. 116.

${ }^{36}$ Lopes, Antão: «Chronica d'el Rey D. Fernando» pp. 125-126, en Collecao de libros inéditos de historia portugueza, Academia Real das sciencias de Lisboa, tomo Iv.

${ }_{37}$ D’Arienzo, Luisa (2003): Gli italiani in portogallo al tempo di Colombo, Istituto Poligrafico dello Stato Roma, p. 58.

${ }^{38}$ En el caso de Manuel (II) Pessagno hay que señalar una aparente incongruencia temporal entre dos documentos. En la carta del 2 de junio de 1385 es calificado como «almirante de nosso irmâo el rey Dom Fernando a que Deus perdoe», rey que murió el 29 de octubre de 1383. Todavía somos informados por Antáo Lopes que las operaciones navales de 1384 no fueron dirigidas por un almirante. La responsabilidad de la flota de galeras ordenada para resistir al bloqueo naval castellano a Lisboa fue entregada a D. Lourenço, arzobispo de Braga. En el viaje de ida a Porto, el capitán de la flota fue Gonçalo Rodrigues de Sousa, alcaide de Monsarraz, y en el viaje de regreso a Lisboa el capitán fue D. Pedro, conde de Trastámara. Micer Manuel Pessanha, heredero del almirantado, era solo capitán de la galera San Jorge. Mario Viana, $O$ almirantado e a jurisdiçâo sobres os homens do mar em Portugal na Idade Média, en Gentes de mar en la ciudad atlántica medieval, Solorzano Bochaca Aguiar eds, p. 330. 
El segundo aspecto crítico del «documento Almeida» es la donación a Lançarote da Franca en 1376, y la confirmación a Lopo Affonso da Franca en 1385, de las «jabonerías negras de la Villa de Tavilla [Tavira] y de Castromarim y de Alcoutim y de la aldea de Martinlongo, en el reino del Algarve». El problema que surge con respecto a esta donación es que se concede 50 años antes de que apareciera por primera vez el monopolio para la producción y venta del jabón en Portugal.

Las saboarias han constituido en Portugal la primera forma de monopolio, concedido por el soberano a un individuo, con la obligación de pagar a cambio una cantidad de dinero ${ }^{39}$. El primer monopolio conocido se remonta a comienzos del siglo Xv en favor del Infante D. Henrique, duque de Vizeu. El privilegio le fue concedido por su padre, el rey D. João I, en principio, en la Ribeira de Santarem en 1424. Años después, en 1433, por concesión de D. Duarte el monopolio de D. Henrique se extendió a todo el país ${ }^{40}$. Antes de esta fecha no se conocen documentos que comprueben donaciones de saboarias a otros individuos.

Un aspecto que parece confirmar que el monopolio del jabón era un instituto totalmente nuevo para Portugal es que tan solo en 1434, en contra de la decisión del ańo anterior de otorgarle el monopolio a D. Henrique, los representantes del pueblo reunidos en las Cortes de Santarem pidieron al nuevo soberano D. Duarte su abolición ${ }^{41}$ «que lhes parecía extranho que do seu aceite e cinza não podesse cada um fazer sabão para despeza de su casa». Sin embargo, el monopolio no fue eliminado.

Solo desde ese momento la donación de las saboarias se transformó en una forma de compensar a personajes por los más diversos motivos: la primera donación conocida la hizo D. Henrique a D. Alvaro de Castro en 1436 como dote por su matrimonio ${ }^{42}$. Y en 1448, Maciote de Bethencourt recibió las saboarias de la isla de Madeira en pago por la cesión de sus derechos sobre la isla de Lanzarote ${ }^{43}$.

De acuerdo con lo que se conoce en la actualidad, todas estas evidencias no permiten aceptar como auténtica la donación de las saboarias de Tavira, Alcoutim y Martinlongo a Lançarote da Franca en 1376, 50 años antes de la creación del monopolio. Lo más probable es que la donación haya tenido lugar por primera vez cien años más tarde, en 1473, en favor de Diogo Lopes da Franca (doc. 6).

39 De Vilhena Barbosa, I. (1842-1843): «Apontamentos para a história das saboarias em Portugal», en Estudos Historicos e Archeologicos, pp. 173-184; Pereira do Carmo, B.: «Apontamentos para a historia das saboarias em Portugal», Revista Universal Lisbonense, t. II, pp. 282-283.

40 Monumenta Henricina, vol. Iv, p. 271.

41 Verissimo Serrao, J.: "História de Portugal (1415-1495)».

${ }^{42}$ Monumenta Henricina, vol. 1 p. 181.

43 Albuquerque, A.: "Primódios da expansão. As viagens do descobrimiento», en História de Portugal, Palas Ed., Lisboa, p. 259. 


\section{El Archivo da Casa dos Franca}

Otro aspecto que hace dudar de la autenticidad de los documentos Almeida es que en ninguna de las 25 principales genealogías de las familias nobles de Portugal escritas entre el siglo XIV y el siglo XIX (doc. 2), se encuentra la noticia de un cargo de almirante otorgado a un Lançarote da Franca o de un descubrimiento suyo de las Islas Canarias. Ni siquiera en la genealogía de los Franca, escrita en 1750 por un descendiente de la familia, el presbítero Alexandre Correia da Franca en su Historia de la Ciudad de Ceuta (doc. 10).

No obstante, a finales del siglo XIX aparece, en manos de António José Maria da Horta Telles Machado da Franca, primer conde de Marim ${ }^{44}$, un «Archivio da Casa dos Franca» que con muchos detalles reconstruye la historia de la familia $\mathrm{Da}$ Franca, supuestamente utilizando antiguos documentos. Las dos transcripciones (doc. 14 y 15) que nos han llegado del Archivo ${ }^{45}$, hoy desaparecido, recogen varias noticias relacionadas con el origen de la familia que, más que falsas, pueden calificarse como pura fantasía. Según el Archivio, por ejemplo, resultaría que el padre de Lançarote da Franca, llegado a Portugal en 1317 junto a Manuel Pessanha, primer almirante de Portugal, era un tal Affonso Franchi o Franche, hijo menor del almirante de Génova Joham Franche. Desafortunadamente, el historiador genovés Foglietta en su historia de Génova recopila, entre 1119 y 1322, el nombre de setenta y cinco almirantes y capitanes al mando de un grupo de galeras y ninguno se llamaba Franche o Franchi ${ }^{46}$, hecho comprensible al considerar que el apellido Franchi aparece por primera vez en Génova recién en 1423.

El contenido del Archivo no es el único dato que hace pensar en la existencia de una sistemática falsificación de la historia de la familia Da Franca por parte de alguno de sus descendientes, probablemente el mismo primer conde de Marim ${ }^{47}$. Un artículo de periódico nos relata que en la subasta de los bienes de la familia, en el que fue adquirido el documento Almeida, había a la venta muchos objetos falsos. Estaba a la venta, por ejemplo, una espada que se suponía del siglo XIV, vendida como si fuera perteneciente al Adail de Tánger, y que, en realidad, era de una época muy posterior, y diez retratos modernos, conmemorativos de varios miembros ilustres de la misma familia, pintados en un estilo que intentaba semejarse a las pinturas antiguas.

${ }_{44}$ El título de conde de Marim fue creado por decreto el 13 de septiembre de 1897 por el rey D. Carlos I de Portugal.

${ }^{45}$ Mascarenhas de Mello, João (1942): «O combate da campina entre Melos e Pessanha». de Dornellas A.: Armas de Familia. Francas, Elucidario Nobiliarchico I, vol. Fevereiro de -1928, n. ${ }^{\circ}$ II p. 44, Comunicação apresentada por Affonso de Dornellas na classe de Letras da Academia das Sciencias de Lisboa em 9 de Julho de 1925.

46 Foglietta, U. (1798): Dialogo sopra il legittimo governo popolare della Repubblica di Genova, Stamperia francese ed italiana, Genova-1650, pp. 53-62.

47 «Un minucioso estudio acerca de la familia Franca realizado por el Capellán de la Casa del Conde de Alte, padre del Conde de Marim, no parecía contener cualquier referencia a un Lançarote da Franca, donatario de las Islas Canarias» de Dornellas, ibidem, p. 44. 
El último aspecto que hace pensar en la falsedad de los documentos es que Fortunato de Almeida no ha presentado nunca los originales, caso que tal vez podría justificarse considerando que los documentos fueron adquiridos en 1916 por José Pereira de Sampaio, director de la Biblioteca Municipal do Porto, y Fortunato de Almeida probablemente solo pudo ver sus transcripciones.

Más problemático resulta explicar por qué los documentos no se encuentran tampoco en las Chancelarias de la Torre do Tombo. Ciertamente, con la llamada «Reforma de Gomes Eanes de Azurara» de 1459, que tenía el objetivo de facilitar la pesquisa en la Torre do Tombo, los registros originales fueron seleccionados, copiados y posteriormente destruidos en el siglo XVI. Sin embargo, la transcripción de las Chancelarias de D. Fernando y de D. João I se llevó a cabo bajo la supervisión de Gomes Eanes de Azurara, uno de los historiadores portugueses más importantes del siglo Xv, especialmente interesado en la expansión ultramarina de Portugal ${ }^{48}$. Por lo tanto, para considerar auténtico el documento Almeida habría que aceptar una de estas dos posibilidades: que en 1459, tan solo cincuenta años después de su redacción, los tres documentos ya hubieran desaparecido de la Torre do Tombo o, como alternativa, que no fueran transcritos por Azurara por no ser considerados importantes, a pesar de que testimoniaban el descubrimiento y el intento de conquista de las Islas Canarias y el honrado fin de un almirante de Portugal peleando contra gaáchos y los castellanos en la isla de Lanzarote.

\section{CONCLUSIONES}

Averiguar la autenticidad de un documento es una tarea compleja, sobre todo al no disponerse del original. El hecho de que algunos elementos de un escrito sean históricamente documentados no es determinante: el primer objetivo de cualquier falsario es esconder su manipulación de la verdad, y la forma más sencilla de hacerlo es mezclar la información falsa con hechos y datos conocidos y aceptados como auténticos. Por este motivo, los datos fidedignos, por específicos que sean, no certifican la autenticidad de un escrito porque podrían ser solo el fruto de la habilidad y competencia del posible falsario.

Parece ser este el caso del «documento Almeida»: unos pocos datos históricamente comprobados, como la fecha y lugar del documento, se mezclan con datos "posiblemente verdaderos», como la referencia a Nuestra Señora a Franca o la concesión de las jabonerías a la familia Franca. Sin embargo, dos acontecimientos, la concesión del título de almirante y de las jabonerías a Lançarote y Lopo Afonso da Franca, deben considerarse «acontecimientos históricamente falsos», por lo menos

48 Eanes de Azurar es autor entre otras obras de la Chronica da tomada de Ceuta y la Chronica do Descobrimento e Conquista da Guiné. 
en el estado actual de nuestros conocimientos. Y obligan a considerar «falso» el documento Almeida, sobre todo en lo que se refiere a la existencia de un almirante Lançarote da Franca, redescubridor de las Islas Canarias.

Si se acepta esta tesis, una información históricamente comprobada, utilizada por el falsario, podría ofrecer una pista para datar su redacción hacia finales del siglo xix. Esta posibilidad podría deducirse del hecho de que el supuesto almirante Da Franca descubriera solo dos de las Islas Canarias. Esta circunstancia se corresponde con la realidad, ya que el primer navegador que navegó las Canarias en época moderna, el genovés Lanzarotto Malocello, en 1339, descubrió solo dos de las siete islas del archipiélago canario, la Insula de Lanzarotus Marocelus y la la forte ventura ${ }^{49}$, mientras que el resto del archipiélago se descubrió solo dos años más tarde, en 1341, por parte de Niccoloso da Recco. Sin embargo, esta noticia fue conocida solo después del hallazgo del mapa de Angelino Dulcert de 1339 en la Biblioteca Nacional de París, acontecimiento que se remonta tan solo a $1885^{50}$. Antes de esta fecha, nada hacía pensar en un descubrimiento del archipiélago en dos etapas sucesivas. Lo que ubicaría la redacción del documento Almeida, si fuera falso, a finales del siglo XIX o a comienzos del siglo XX.

Recibido: 07-02-2019. Aceptado: 11-04-2019

49 Boccaccio, G.: «De Canaria» en Quartapelle, A. 400 años de crónicas de las islas Canarias, pp. 49-54.

${ }_{50}$ Fernández Duro, C. (1888): Descubrimiento de una carta de marear, española, del año 1339. Su autor Angelino Dulceri ó Dulcert, Real Academia de Historia, p. 287. 
